\title{
CRITICAL ROLE OF NASAL TISSUE-RESIDENT MEMORY CD4+ TH17 CELLS IN VACCINE- INDUCED PROTECTION AGAINST PNEUMOCOCCAL COLONIZATION
}

Joanne M. O’Hara ${ }^{1}$, Naresh Redhu', ${ }^{1,2}$, Elaine Cheung ${ }^{1}$, Nancy Robertson ${ }^{3}$, Muriel Herd ${ }^{1}$, Evan Conaway ${ }^{2}$, Bruce Horwitz ${ }^{4}$, Richard Malley1,

${ }^{1}$ Boston Children's Hospital and Harvard Medical School, Division of Infectious Diseases, Boston, USA, ${ }^{2}$ Brigham and Women's Hospital and Harvard Medical School, Department of Pathology, Boston MA, USA, Harvard Medical School, Department of Genetics, Boston, USA \& “Brigham and Women's Hospital and Harvard Medical School, Division of Emergency Medicine, Boston, USA

\begin{tabular}{|c|}
\hline Introduction \\
\hline $\begin{array}{l}\text { Pneumococcal Disease: Current vaccine strategies and } \\
\text { challenges }\end{array}$ \\
\hline 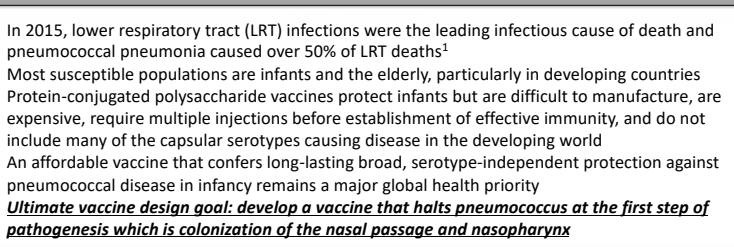 \\
\hline
\end{tabular}

WCV elicits $\mathrm{CD} 4^{+}$Th17 cells that protect against nasal challenge
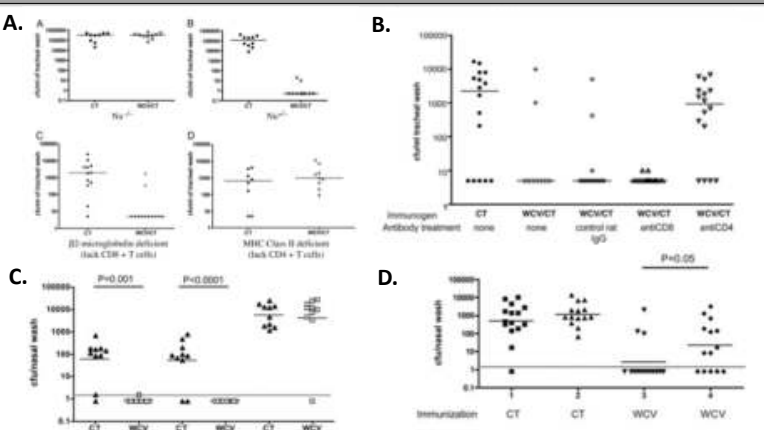

D.

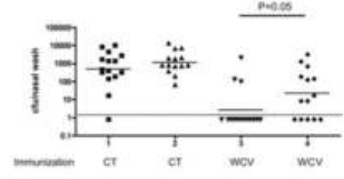

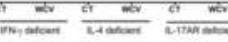

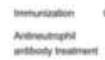

Figure 1: Pneumococcal Whole Cell Vaccine (WCV) immunized mice A) deficient in T-cells, or deficiei specifically in $\mathrm{CD}^{+} \mathrm{T}$ cells $\mathrm{s}^{2}$ B) treated with a CD4-depleting antibody during infection ${ }^{2} \mathrm{C}$ ) lack
IL-17A receptor ${ }^{3}$, D) or treated with neutrophil depleting antibod $y^{3}$, are not protected from

Background: Tissue resident memory $\mathrm{CD}^{+} \mathrm{T}$ cells $(\mathrm{Trm})$ provide protection against pathogens at mucosal surfaces

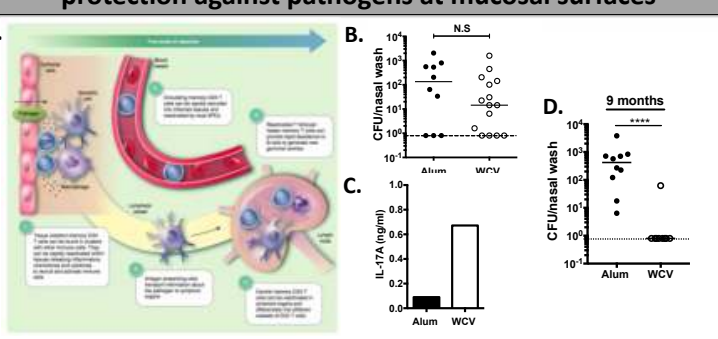

Figure 2: A) Protective role of memory $\mathrm{CD}^{4} T$ cell subsets ${ }^{4}$. B) Adoptive transfer of splenocytes and
cervical lymph node cells from WCV immunized mice into Rag1 $1 /$ mice does not provide significant protection to recipient mice against nasal colonization with pneumococcus. C) Despite detection of
high levels of WVV-induced LI-17A in the cervical lymph nodes of recipient mice. D) Mice immunized months after their last immunization, indicating that wCV provides long-lasting protection at months after their
mucosal surfaces.

Hypothesis: Parenteral immunization with WCV generates nasal $C D 4^{+}$ Trms that provide protection against pneumococcal nasal colonization

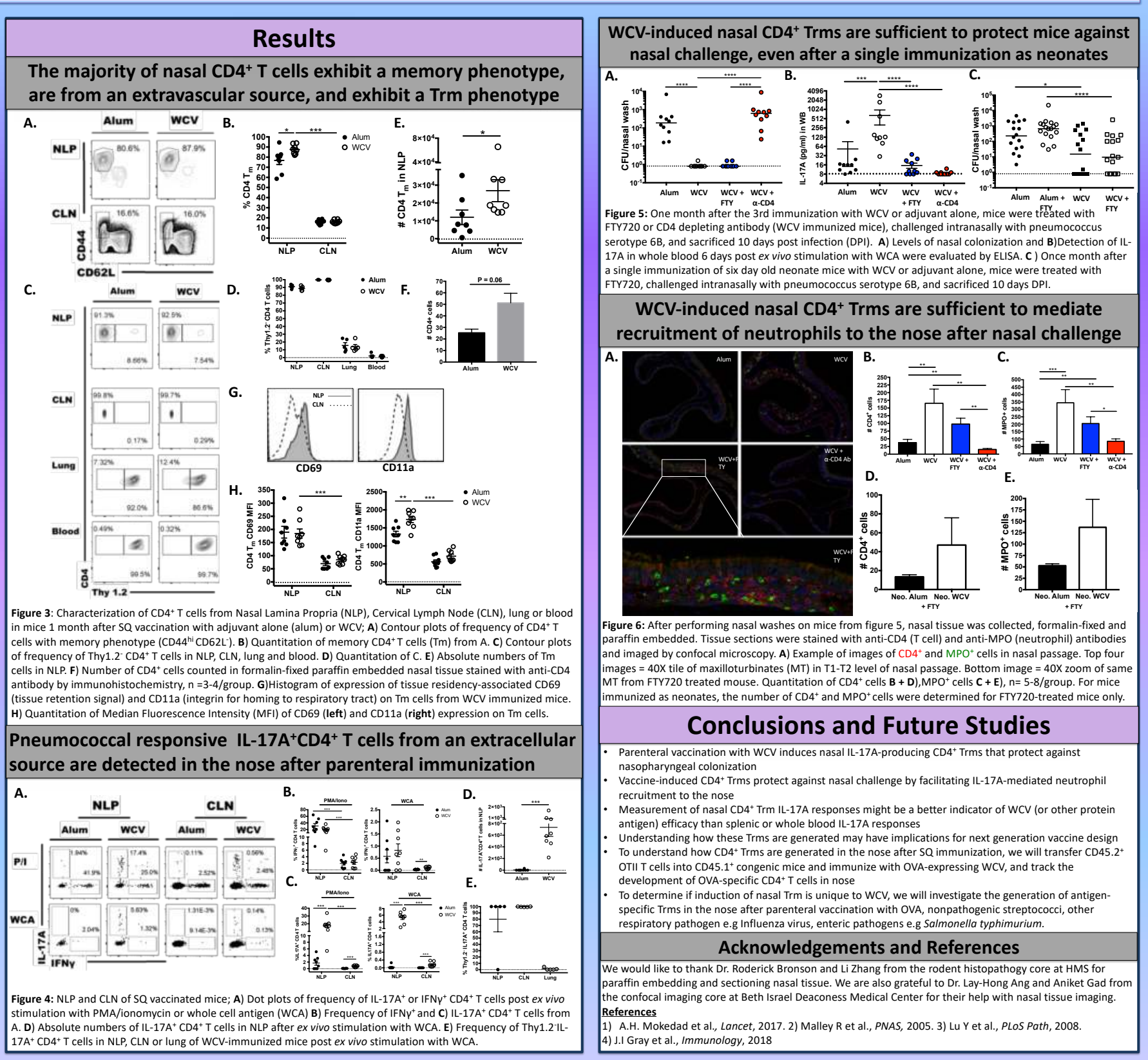

